\title{
Surgical treatment of tethered cord syndrome-comparing the results of surgeries with and without electrophysiological monitoring
}

\author{
Gábor Fekete ${ }^{1}$ László Bognár ${ }^{1}$ László Novák ${ }^{1}$
}

Received: 5 December 2018 / Accepted: 18 March 2019 / Published online: 8 April 2019

(C) The Author(s) 2019

\begin{abstract}
Purpose To compare the short- and long-term outcomes after surgical treatment of tethered cord syndrome with and without electrophysiological monitoring.

Method We collected the preoperative data of 102 tethered cord surgeries of 91 patients. We compared the outcomes regarding the presence of intraoperative electrophysiology, the types of surgeries and the preoperative neurological condition. We also analysed the long-term outcomes in the cases of 69 patients.

Results We found that intraoperative electrophysiology can reduce the perioperative surgical risk significantly (from 9.4 to $2.9 \%$, $p<0.001$ ), and electrophysiology is also beneficial in avoiding long-term progression in $88.7 \%(p=0.03341)$.

Conclusion Tethered cord surgeries are safe and effective. With the use of intraoperative electrophysiology, the risk of postoperative worsening is as low as $2.9 \%$, and long-term progression can be avoided in the majority of the patients.
\end{abstract}

Keywords Tethered cord · Neurosurgery $\cdot$ Electrophysiology $\cdot$ Paediatric

\section{Introduction}

Tethered cord syndrome is a progressive anomaly resulting in neurological, orthopaedic and urological dysfunction caused by the anchoring of the spinal cord by different pathologies [2]. Though the syndrome is diagnosed mainly in childhood, milder cases might be revealed in adulthood. The incidence of spinal dysraphism resulting in spinal cord tethering is one per 4000 births, and slight female dominance is present [13]. Formerly, the diagnostic criteria were a conus position below L.I-II level with or without thickened film terminale; currently, any fixation of the spinal cord in the spinal canal due to primary or secondary cause can be defined as tethered cord

László Novák

novaklaszlo@hotmail.com

Gábor Fekete

novaklaszlo@hotmail.com

László Bognár

bognarlaszlo@t-email.hu

1 Department of Neurosurgery, University of Debrecen, Móricz Zs. krt, Debrecen 22, Hungary
[18]. The underlying pathophysiological processes include decreased blood flow, impaired oxidative metabolism and abnormal glucose metabolism [6, 21, 23].

There is a slight difference between the leading symptoms between children and adults. Among children, the most frequent symptoms are sensory and motor deficit, vegetative impairment (bladder and/or bowel voiding dysfunction) orthopaedic deformities, often combined with skin alterations. The coexistence of skin anomalies and dysraphisms can be explained by the common embryologic origin of the skin and the nervous system [4]. In adulthood, pain is more common, and they can experience motor deficit quite often. However, all the symptoms can occur in both age groups. The symptoms are usually progressive. In childhood, symptoms are often worsening during growth spurts; while among adults, stretching or trauma can elicit the complaints. Considering the progressive nature of the syndrome, surgical treatment can rarely be avoided. The results of the studies of Bui et al. recommend that in childhood, the diagnosis of spinal cord tethering alone should be an indication for surgery to avoid neurological deficits [2]. The aim of the operation is the detethering of the spinal cord and abolish the 
tension of the myelon. This may result in the reversion of the hypoxia and metabolic changes and in the recovery of neurological functions [18]. The expectable improvement depends on the degree of preoperative neurological deficit and the duration of the symptoms. Long-term severe deficits recover rarely, while shortterm mild deficits can completely disappear [23].

The surgical solution can be the transection of a certain bundle, most commonly a thickened film terminale, but there are also cases where complicated pathology causes the tethering. It can involve different degrees of neural tube defects (meningocele, meningomyelocele, lipomyelocele, etc.), intraspinal lipomas. We also have to pay attention to the relatively high rate of reoperations, where primary surgical treatment aimed the closure of the dysraphism. In the latter cases, significant scar tissue formation can lead to complicated surgeries. The risk of postoperative deterioration may be lower using intraoperative electrophysiological monitoring. In this paper, we compare the short- and long-term outcomes of tethered cord surgeries performed in two different eras, i.e. without and with electrophysiological monitoring by the same senior surgeon (László Bognár).

\section{Materials and methods}

\section{Patient data}

We analysed the outcomes of 102 surgeries of 91 patients. The average age at the time of the surgeries was 8.44 years $(0-$ 59.43 years); 89 operations were performed in childhood, 13 on adults. The male/female ratio was $46 / 45$. Thirty-two surgeries were done without electrophysiological monitoring, 70 with electrophysiological control. The operations were done by the same surgeon, having sufficient surgical experience from before the analysed time frame (leading Hungarian paediatric neurosurgeon, more than 10 years of experience in detethering surgeries prior to the examined period); thus, the effect of a learning curve on the outcomes could be excluded. The operated pathologies are summarised in Table 1.

We analysed the early postoperative outcomes, especially regarding the neurological symptoms. The longterm results were collected in 69 patients. We examined the rate of reoperations. We also compared our results of neurologically intact patients with patients with neurological deficit. We analysed the differences of outcomes in the cases where during surgery only one specific bundle (thickened filum terminale or dermal sinus) could have been identified as the cause of tethering with the surgeries where complicated pathologies had to be solved. The results of these groups regarding the presence of electrophysiological control were also matched.
Table 1 Surgical interventions defined by the underlying pathologies

\begin{tabular}{lc}
\hline Type of surgery & Number of operations \\
\hline Resection of intraspinal lipoma & 42 \\
Transection of a specific bundle & 31 \\
Scar tissue release & 18 \\
Scar tissue release with lipoma resection & 2 \\
Dyastematomyelia & 2 \\
Epidermoid tumour resection & 1 \\
Dermoid tumour resection & 1 \\
Meningicele reconstruction & 2 \\
Detethering not possible & 3 \\
Total & 102 \\
\hline
\end{tabular}

\section{Electrophysiological monitoring}

During the surgeries, we used Inomed ISIS Portable intraoperative electrophysiological device (Inomed, Germany). We applied direct electrical stimuli on the bundles to be transected and detected the responses with needle electrodes in the muscle groups of both lower extremities. Responses were also detected at the anal sphincter. We routinely used 14 channels (m. gluteus magnus, m. quadriceps femoris, m. semitendinosus, $m$. tibialis anterior, $m$. triceps surae, m. abductor hallucis and the anal sphincter on both sides) [5]. We applied 200 us pulse width stimuli up to $2.9 \mathrm{~mA}$, and we repeated the stimulation at $3-\mathrm{Hz}$ frequency. We also used free run EMG to detect the possible traction during the surgical manipulation. In eight cases, we also examined the bulbocavernosus reflex for monitoring the integrity of S.2.S.4. fibres. However, as this modality has no mapping value, which means that the changes in the responses occur only after the transection, it did not help to decide which bundles are safe to be cut. In addition, we can elicit the same reflex by stimulating the sensory afferents of the reflex arch [3], which has mapping value (potential impairment can be predicted before the transection). Thus, taking into consideration the value and the difficulties of pudendal nerve stimulation especially in very young female patients, we did not continue to use this modality routinely.

\section{Statistics}

We created two groups based on whether the surgery was done with intraoperative electrophysiological monitoring (IOM) or not (no IOM). We applied Pearson's chi square test with Yates' continuity correction where it was necessary to compare the results of the different groups. Difference was considered significant when $p$ value was below 0.05 . 


\section{Results}

All of the patients were operated on due to tethered cord syndrome. The underlying pathology is summarised in Table 1 . The preoperative neurological symptoms are shown in Table 2.

The number of the reoperations due to symptomatic retethering was 16 out of 102 . In four cases, the primary operation was done in another institute; 12 of them developed recurrent symptoms in the specified follow-up period. With the correction of this factor, the rate of reoperation was $19.6 \%$. In the electrophysiological group, we found significantly lower rate of reoperation $(8.6 \%$ versus $23.8 \%, p=0.02567)$.

Our overall risk for early neurological deterioration was $7.8 \%$. With electrophysiological monitoring, we could lower the risk from 12.5 to $5.7 \%$, though the difference was statistically not significant $(p=0.2369)$. The postoperative deficit affected the vegetative functions in seven cases, and gait functions in one case. In three cases, the postoperative worsening recovered completely; thus, the overall permanent surgeryrelated complication rate was $4.9 \%, 2.9 \%$ in the IOM group and $9.4 \%$ in the not monitored group $(p<0.001)$. We also experienced improvement in 13 cases, all of them in the electrophysiologically controlled group $(p=0.02203)$.

We collected the long-term outcomes in the cases of 69 patients involving 79 surgeries. The average follow-up period was 45.72 months (1.5-150 months). We experienced neurological progression in $17.7 \%$ of the cases. In the IOM group, it was significantly lower $(11.3 \%$ versus $30.8 \%, p=0.03341)$. Improvement was present in 13.9\%: in the IOM group, $18.9 \%$ and in the no IOM group, 3.8\%; however, this difference is not significant $(p=0.06995)$. In terms of no progression, our overall ratio for progression-free follow-up was $82.3 \%$, significantly better with electrophysiology $(88.7 \%$ versus $69.2 \%$ $p=0.03341$ ). Our overall results are summarised in Fig. 1.

We operated on 44 patients (43\%) with preventive aim. These paediatric patients were asymptomatic, and spinal cord tethering was either accidental finding, or revealed by screening based on minor signs, like skin alterations at the lumbar region. In the early postoperative time, $4.5 \%$ of them developed neurological deficit (IOM group 0\%, no IOM group $8.7 \%, p=0.5101)$. Long-term follow-up was available in
$86.4 \%$ of these patients. We detected progression in $23.7 \%$ (IOM group 10\%, no IOM 38.9\%, $p=0.03649$ ). In this group, the progression-free ratio of the patients was $76.3 \%$ (IOM group $90 \%$, no IOM group $61.1 \%, p=0.03649$ ).

In 58 cases $(57 \%)$, the patients had neurological deficit prior to surgery. After the operation, $5.2 \%$ of them had worsening (IOM group $4.1 \%$, no IOM group $11.1 \%, p=0.955$ ). Improvement was detected in $19 \%$, all of them in the IOM group (22.4\% of these patients, $p=0.2642$ ). Long-term follow-up data were available in $70.7 \%$. Progression was present in $14.6 \%$ (IOM group $12.1 \%$, no IOM group $25 \%, p=$ $0.7135)$. Improvement occurred in $22 \%$ without significant difference between the two groups (IOM group $24.2 \%$, no IOM group $12.5 \%, p=0.8074)$. The rate of progression-free patients was $85.4 \%$ (IOM group $87.9 \%$, no IOM group $75 \%$, $p=0.7135$ ). The long-term progression ratio between the symptomatic and asymptomatic patients was statistically not significant $(p=0.4607)$.

In $30.4 \%$ of our patients during the surgery, a definitive bundle could be identified as the cause of spinal cord tethering. Among these patients, we detected deterioration in $9.7 \%$ of the patients (IOM group 6.3\%, no IOM group 13.3\%, $p=$ 0.9738 ). Improvement was detected in $16.1 \%$, all of them in the IOM group (31.3\% of these patients, $p=0.01807$ ). Longterm follow-up is available in $77.4 \%$. Progression occurred in $12.5 \%$ (all in the no IOM group, $25 \%$ of these patients, $p=$ 0.06408 ). Long-term improvement was present in $8.3 \%$, all in the IOM group $(16.7 \%$ of these patients, however the difference is statistically not significant, $p=0.1396$ ). The progression-free ratio was $87.5 \%$ (IOM $100 \%$, no IOM $75 \%, p=0.06408)$.

Patients with complex pathologies (69.6\% of the cases) showed early postoperative deterioration in $5.6 \%$ (IOM group $3.7 \%$, no IOM group $11.8 \% p=0.2087$ ). Improvement was detected in $11.3 \%$, all in the IOM group (14.8\% of these patients, $p=0.2131$ ). Long-term follow-up is available in $77.5 \%$. Progression occurred in $20 \%$ (IOM group 14.3\%, no IOM group 38.5\% $p=0.05687$ ). Long-term amelioration was present in $16.4 \%$ (IOM group 19\%, no IOM group 7.7\%, $p=$ $0.3335)$. The ratio of patients free of progression was $80 \%$ (IOM group $85.7 \%$, no IOM 61.5\%, $p=0.05687$ ).

\begin{tabular}{lcc}
\hline Symptom & Number of patients & Ratio (no. of patients/all patients) \\
\hline No deficit & 44 & $43.14 \%$ \\
Vegetative dysfunction & 44 & $43.14 \%$ \\
Paresis & 33 & $32.35 \%$ \\
Sensory deficit & 7 & $6.86 \%$ \\
Pain & 6 & $5.88 \%$ \\
Gait disturbance & 3 & $2.94 \%$ \\
Mixed symptoms & 30 & $29.41 \%$ \\
\hline
\end{tabular}


Fig. 1 Summary of overall results

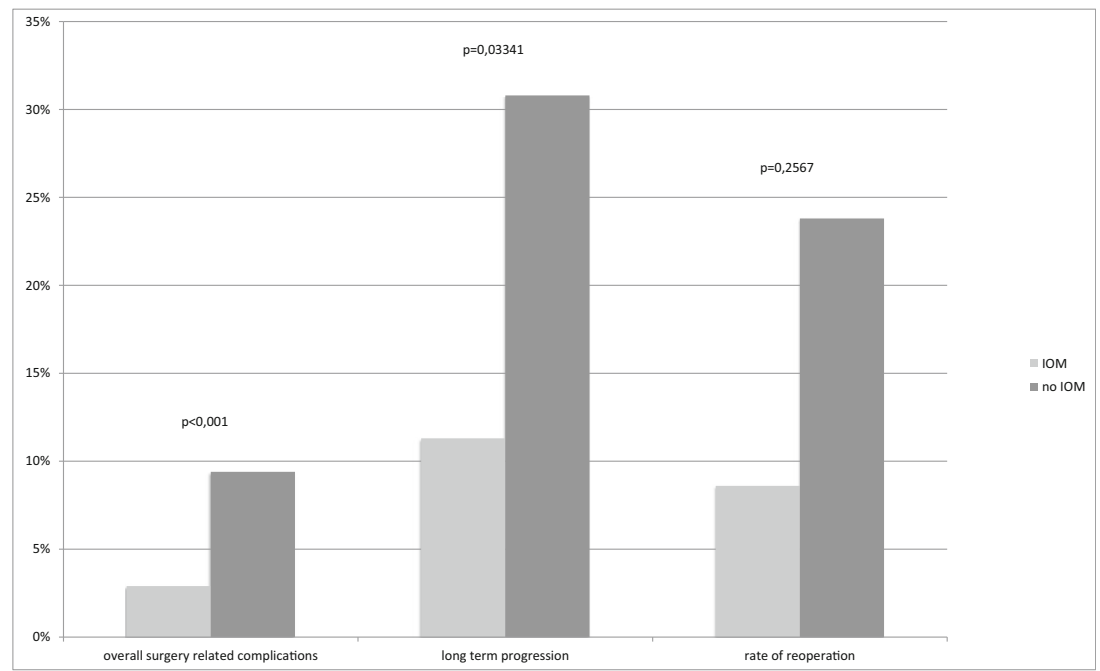

\section{Discussion}

Tethered cord syndrome is diagnosed mainly in childhood and can be associated with genetic abnormalities like trisomy 8 , chromosome 21 and 22 abnormalities and neurofibromatosis type I [1].

In children, symptoms may worsen at the times of growth spurts; while among adults, certain circumstances can precipitate the complaints [15], like stretching positions or spine trauma. The cause of late diagnosis of tethered cord syndrome might be that the threshold of stretching is not reached until certain events. Trauma may precipitate symptoms, while mild, transient tension needs time to reach a cumulative impairment in blood flow [21, 23]. Surgery can conserve the baseline neurological status in most of the cases. Voiding functions may improve among children especially under 1 year of age [9], while pain and sensory deficits respond well to detethering in adulthood $[12,15]$. Timing of surgery among adults is controversial [7]; however, symptomatic cases may need intervention in any age [22]. Though recent papers publish good results with spinal shortening procedures among adult patients $[8,16,20]$, we believe that the aim of the operation should be always the detethering of the spinal cord. The effect of the intervention is usually satisfying, but the extent of possible improvement depends on the severity of preoperative deficits [2]. Secondary operations have higher risk for neurological deterioration, and long-term benefits are also less favourable $[10,11]$. Operation can be in certain cases only the transection of a bundle, but in many cases, the pathology is surgically more complex, involving intraspinal lipoma, neural tube defects or scar tissue formation from earlier surgeries. Latter cases are more challenging and have higher risk for retethering $[11,17]$.

In our study, we compared the short- and long-term results in the cases of surgeries with and without electrophysiological monitoring. Though earlier certain authors stated that intraoperative monitoring during the surgical release of tethered cord has no significant benefit [14], our data shows that electrophysiology could reduce significantly the risk postoperative neurological deficit from 9.4 to $2.9 \%$. We also analysed the results in long-term follow-up. We found that the surgery could avoid progression in $82.3 \%$ of patients. Electrophysiology could significantly improve the results in this aspect, as well. Applying this examination, the progression-free ratio of the patients rose significantly from 69.2 to $88.7 \%$.

The long-term improvement was based on the neurological examination on the follow-up visits. We suppose that in the early postoperative neurological conditions are biased by pain, the presence of catheter, restricted mobility, etc. On the follow-up visits, these factors are not present, which may cause the patient to feel better; and neurological examination can also confirm better functions, but on the other hand, recovery of the spinal cord functions may also have its role. The short-term outcomes of tethered cord surgeries are usually not consistently documented. Early postoperative deficits have good chance to recover. Lee et al. mention $6.8 \%$ of early neurological worsening $3.4 \%$ recovering by the time of discharge [12]. Besides the neurological deterioration, they report $15.2 \%$ risk of cerebrospinal fluid leakage and an infection rate of $8.4 \%$ based on 59 surgeries. Hsieh et al. found one transient urological dysfunction out of seven operations (14\%) that recovered in 4 months [9], while Pang et al. reported a rate of $4.76 \%$ of postoperative urological dysfunction [15]. Analysing the outcomes of 326 paediatric cases, Shang et al. found postoperative urinary retention in six cases (1.8\%), lower extremity numbness in nine cases $(2.8 \%)$ and lower extremity weakness in three cases (1\%) [19].

In the cases of neurologically intact patients, the early deterioration ratio was $11.4 \%$, slightly better results with intaoperative monitoring, but the difference was statistically not significant. However, we have to mention that in long term, all of the 
monitored patients recovered and reached the preoperative neurological condition; while among those patients, who were not monitored, one out of the three recovered. Long-term progression was present in $23.7 \%$, which is higher than the average. This is probably because of the no deficit baseline condition; thus, any new symptom means progression.

In this group, the benefits of IOM could be proved, as the progression ratio could be reduced significantly from 38.9 to $10 \%$, which means that complete untethering was feasible in more cases, at the same time with reducing the risk of postoperative worsening.

Patients with preoperative deficit worsened only in 5.2\%. IOM also showed benefits in this group, as adverse events reduced from 11.1 to $4.1 \%$, and the presence of long-term progression occurred in $14.6 \%$, IOM reducing the ratio from 24.2 to $12.5 \%$. However, these differences were not proved significant by statistical analysis.

It has to be noted, that though the difference in long-term progression ratio between the symptomatic and asymptomatic patients is statistically not significant, we believe that this is an unexpected finding and needs further investigation.

Surprisingly, we detected higher postoperative deterioration in the cases where a certain bundle was cut, compared to the operation of complex pathologies (12.9\% vs. $5.6 \%)$. This is also an unexpected finding and warrants further analysis. In both groups, IOM improved the outcomes, however, not significantly. Longterm results showed that progression was present in $12.5 \%$, but all of them occurred in the no IOM group, while none of the monitored patients worsened in long-term. In the cases of complex pathologies, the long-term results showed a progression risk of $20 \%$, IOM reducing the ratio from 38.5 to $14.3 \%$.

We also have to mention that improvement was also detected in certain cases. Early improvement was present in 13 cases $(12.7 \%)$, all of them among monitored patients. In longterm aspects, amelioration was present in $13.9 \%$, mostly among monitored patients. The chance for improvement was more or less the same among patients with bundle transection and with complex pathology. The role of IOM was more stressed among patients with bundle transection, as in this group improvement occurred only among monitored patients.

Though the rate of reoperation was also significantly lower in the IOM group, we have to note that the surgeries without electrophysiology were done between 2005 and 2011, while the monitored surgeries were routinely performed after 2011; thus, the longer follow-up time could influence the reoperation rate.

\section{Conclusion}

Tethered cord syndrome is treated by surgical intervention in the majority of cases. Considering the natural history of this syndrome in childhood, preventive surgery is recommended. Based on our data, the risk of the operation could be reduced by intraoperative electrophysiological examinations. Monitoring is also beneficial in terms of avoiding long-term progression and in reducing the number of reoperations. Our results could be slightly biased by the fact that the not monitored surgeries happened in an earlier period, which leads to longer follow-up period, and more chance to develop negative results concerning reoperation rate and long-term deterioration. On the other hand, the positive results could be reduced by the fact that patients with no progression tend to skip follow-up visits. Taking these details into consideration, our results show that electrophysiology can reduce the surgical risk and the rate of reoperations significantly, and has also major benefit in the aspect of long-term progression. Our data show that surgery with monitoring has $2.9 \%$ risk of deterioration, and progression can be avoided in $88.7 \%$ of the patients.

Funding Information Open access funding provided by University of Debrecen (DE).

\section{Compliance with ethical standards}

Conflict of interest The authors have no conflict of interest.

Open Access This article is distributed under the terms of the Creative Commons Attribution 4.0 International License (http:// creativecommons.org/licenses/by/4.0/), which permits unrestricted use, distribution, and reproduction in any medium, provided you give appropriate credit to the original author(s) and the source, provide a link to the Creative Commons license, and indicate if changes were made.

\section{References}

1. Bassuk AG, Craig D, Jalali A, Mukhopadhyay A, Kim F, Charrow J, Kessler JA (2005) The genetics of tethered cord syndrome. Am J Med Genet A 132A(4):450-453

2. Bui CJ, Tubbs RS, Oakes WJ (2007) Tethered cord syndrome in children: a review. Neurosurg Focus 23(2):1-9

3. Deletis V, Shils J (2002) Neurophysiology in neurosurgery: a modern intraoperative approach, 1st edn. Copyright 2002 Elsevier Science (USA) chapter 9, p 206

4. Drolet DA, Chamlin SL, Garzon MC, Adams D, Baselga E, Haggstrom AN, Holland KE, Horii KA, Juern A, Lucky AW, Mancini AJ, Mc Cuaig C, Metry DW, Morel KD, Newell BD, Nopper AJ, Powell J, Frieden IJ (2010) Prospective study of spinal anomalies in children with infantile hemangiomas of the lumbosacral skin. J Pediatr 157(5):789-794

5. Fekete G, Novák L, Erőss L, Fabó D, Bognár L (2015) Intraoperativ electrophysiological monitoring during neurosurgery on eloquent structures. (Article in Hungarian). Ideggyogy Sz 68(12):37-45

6. Filippidis AS, Kalani MY, Theodore N, Rekate HL (2010) Spinal cord traction, vascular compromise, hypoxia, and metabolic derangements in the pathophysiology of tethered cord syndrome. Neurosurg Focus 29(1):1-5

7. Hertzler DA II, DePowell JJ, Stevenson CB, Mangano FT (2010) Tethered cord syndrome: a review of the literature from embryology to adult presentation. Neurosurg Focus 29(1):E1. https://doi.org/ 10.3171/2010.3.focus1079 
8. Hou Y, Sun J, Shi J, Guo Y, Wang Y, Shi G, Xu G (2018) Clinical evaluation of an innovative operative procedure in the treatment of the tethered cord syndrome. Spine J 18(6):998-1004. https://doi. org/10.1016/j.spinee.2017.10.009

9. Hsieh MH, Perry V, Gupta N, Pearson C, Nguyen HT (2006) The effects of detethering on the urodynamics profile in children with a tethered cord. J Neurosurg 105(5):391-395

10. Hsieh PC, Stapleton CJ, Moldavskiy P, Koski TR, Ondra SL, Gokaslan ZL, Kuntz C (2010) Posterior vertebral column subtraction osteotomy for the treatment of tethered cord syndrome: review of the literature and clinical outcomes of all cases reported to date. Neurosurg Focus 29(6):E6. https://doi.org/10.3171/2010.4. focus 1070

11. Klekamp J (2011) Tethered cord syndrome in adults - clinical article. J Neurosurg Spine 15:258-270. https://doi.org/10.3171/2011.4. spine 10504

12. Lee GY, Paradiso G, Tator CH, Gentili F, Massicotte EM, Fehlings MG (2006) Surgical management of tethered cord syndrome in adults: indications, techniques, and long-term outcomes in 60 patients. J Neurosurg Spine 4:123-131. https://doi.org/10.3171/spi. 2006.4.2.123

13. McGirt MJ, Mehta V, Garces-Ambrossi G, Gottfried O, Solakoglu C, Gokaslan ZL, Jallo GI (2009) Pediatric tethered cord syndrome: response of scoliosis to untethering. J Neurosurg Pediatr 4(3):270 274

14. McLone DG, La Marca F (1997) The tethered spinal cord: diagnosis, significance, and management. Semin Pediatr Neurol 4:192208. https://doi.org/10.1016/S1071-9091(97)80037-X

15. Pang D, Wilberger JE Jr (1982) Tethered cord syndrome in adults. J Neurosurg 57:32-47. https://doi.org/10.3171/jns.1982.57.1.0032

16. Safaee MM, Winkler EA, Chou D (2017) Mini-open spinal column shortening for the treatment of adult tethered cord syndrome. J Clin Neurosci 44:315-319. https://doi.org/10.1016/j.jocn.2017.07.037
17. Samuels R, McGirt MJ, Attenello FJ, Garcés Ambrossi GL, Singh N, Solakoglu C, Weingart JD, Carson BS, Jallo GI (2009) Incidence of symptomatic retethering after surgical management of pediatric tethered cord syndrome with or without duraplasty. Childs Nerv Syst 25:1085-1089. https://doi.org/10.1007/s00381-009-0895-6

18. Sanchez T, John RM (2014) Early identification of tethered cord syndrome: a clinical challenge. J Pediatr Health Care 28(3):e23e33. https://doi.org/10.1016/j.pedhc.2013.06.007

19. Shang AJ, Yang CH, Cheng C, Zhang YZ, Gao HH, Bai SC (2019) Microsurgical efficacy in 326 children with tethered cord syndrome: a retrospective analysis. Neural Regen Res 14(1):149155. https://doi.org/10.4103/1673-5374.243720

20. Steinberg JA, Wali AR, Martin J, Santiago-Dieppa DR, Gonda D, Taylor W (2017) Spinal shortening for recurrent tethered cord syndrome via a lateral retropleural approach: a novel operative technique. Cureus 9(8):e1632. https://doi.org/10.7759/cureus.1632

21. Stetler WR, Park P, Sullivan S (2010) Pathophysiology of adult tethered cord syndrome: review of the literature. Neurosurg Focus 29(1):1-5

22. Tseng JH, Kuo MF, Kwang Tu Y, Tseng MY (2008) Outcome of untethering for symptomatic spina bifida occulta with lumbosacral spinal cord tethering in 31 patients: analysis of preoperative prognostic factors. Spine J 8:630-638. https://doi.org/10.1016/j.spinee. 2005.11.005

23. Yamada S, Won DJ, Pezeshkpour G, Yamada BS, Yamada SM, Siddiqi J, Colohan ART (2007) Pathophysiology of tethered cord syndrome and similar complex disorders. Neurosurg Focus 23(2): $1-9$

Publisher's note Springer Nature remains neutral with regard to jurisdictional claims in published maps and institutional affiliations. 